\title{
Quantitative proteomic analysis of peripheral blood mononuclear cells in rheumatoid arthritis
}

\author{
Xinqiang $\mathrm{S}^{1,2,3 *}$, Kaiming $\mathrm{L}^{1}$, Lei $\mathrm{Ch}^{1}$, TK $\mathrm{Lim}^{2}$, Y Mun Lee ${ }^{2}$ and Yuan $\mathrm{L}^{4 *}$ \\ ${ }^{1}$ Department of Biological Sciences, Xinyang Normal University, Xinyang, China \\ ${ }^{2}$ Department of Biological Sciences, National University of Singapore, Singapore \\ ${ }^{3}$ Institute for Conservation and Utilization of Agro-bioresources in Dabie Mountains, Xinyang, China \\ ${ }^{4}$ State Key Laboratory of Toxicology and Medical Countermeasures, Institutes of Pharmacology and Toxicology, Academy of Military Medical Sciences, China
}

\begin{abstract}
In order to identify proteins differentially expressed in rheumatoid arthritis patients and healthy controls, we used isobaric tagging for relative and absolute protein quantification (iTRAQ) to generate quantitative protein profiles from peripheral blood mononuclear cells (PBMCs) from 10 patients with rheumatoid arthritis and 10 healthy donors. Proteins were extracted, concentrated, pooled, labeled with iTRAQ reagents and subjected to multi-dimensional chromatographic fractionation followed by tandem mass spectrometry. A total of 3,208 proteins were identified based on ProteinPilot ${ }^{\text {TM }} 3.0$ software and the International Protein Index (human 3.62) database. Of these, 83 proteins differed at least 2-fold in expression levels between patients and controls. These results indicate that iTRAQ-based technology can serve as a useful aid for identification and quantification of disease-linked proteins from PBMCs. Several proteins, such as serotransferrin, clusterin, annexin A2, and heterogeneous nuclear ribonucleoprotein A2/B1, may be served as biomarker candidates.
\end{abstract}

\section{Introduction}

Rheumatoid arthritis is an autoimmune inflammatory rheumatic disease that affects many tissues and organs and causes chronic synovial inflammation, eventually leading to joint destruction and disability [1-4]. The pathogenesis of rheumatoid arthritis is quite complex and involves genetic and environmental factors. One of the main goals of research on this disease is to identify biomarkers that can shed light on disease onset and progression as well as improve diagnosis, treatment and prognosis.

Several studies implicate lymphocytes in the pathology of rheumatoid arthritis [5-8]. Therefore, we wanted to focus on peripheral blood mononuclear cells (PBMCs) and compare their proteomic profiles from patients and healthy controls. To avoid the problems of high background and low sensitivity associated with two-dimensional electrophoresis and other proteomic approaches used previously [911] to examine PBMCs in patients with rheumatoid arthritis, we chose the method of isobaric tagging for relative and absolute quantitation (iTRAQ). This has proven to be a powerful new tool for proteomic research in many autoimmune diseases [10,12-16]. Up to eight tags can be used in multiplex iTRAQ $[17,18]$, and the large amounts of data emerging from tandem mass spectrometry analysis can be analyzed using bioinformatics. Despite its efficiency as a protein discovery tool, iTRAQ has yet to be applied to rheumatoid arthritis based on our review of the literature.

Here we used iTRAQ-based quantitative proteomic analysis and bioinformatics-based protein identification in order to identify proteins linked to rheumatoid arthritis. We identified these proteins by comparing proteomic profiles of PBMCs from patients and healthy controls.

\section{Methods}

\section{Patients}

PBMCs were isolated from 10 patients with rheumatoid arthritis (five men; mean age, $45 \mathrm{yr}$; age range, 36 to $56 \mathrm{yr}$. five women; mean age, $47 \mathrm{yr}$; age range, 39 to $55 \mathrm{yr}$ ) who fulfilled the American College of Rheumatology Revised Criteria for Rheumatoid Arthritis, as well as from 10 healthy controls who were age- and sex-matched with the patients. Patients had no history of other immune diseases, such as ankylosing spondylitis, systemic lupus erythematosus, or multiple sclerosis. Patients had not received any drug treatment prior to blood sample collection.

All participants provided written informed consent for this study, which was performed at Xinyang Normal University and Xinyang First People's Hospital (Railway Hospital) in China. The study protocol was approved by the institutional research ethics committees at both study sites.

\section{PBMC isolation and protein extraction}

Venous blood $(4 \mathrm{~mL})$ was collected from all patients and controls into EDTA anticoagulant tubes. PBMC were isolated using lymphocyte separation medium following the manufacturer's instructions

Correspondence to: Xinqiang S, Department of Biological Sciences, Xinyang Normal University, Xinyang, China 464000. E-mail: xqsong2012@126.com and Luo Y, State Key Laboratory of Toxicology and Medical Countermeasures, Institutes of Pharmacology and Toxicology, Academy of Military Medical Sciences, Beijing 100850, China, E-mail: luoyuan2006@163.com

\section{Key words: $i T R A Q$, Proteomics, Rheumatoid Arthritis}

Received: December 20, 2017; Accepted: January 16, 2018; Published: January 19,2018 
(Cedarlane Laboratories, Hornby, Ontario, Canada). Total protein was extracted from PBMCs, and concentration was measured using the BCA protein assay kit (Pierce Biotechnology, Rockford, IL, USA). Pools of $100 \mu \mathrm{g}$ of total protein from patients and controls [19] were prepared and analyzed using iTRAQ, respectively.

\section{iTRAQ proteomics}

Protein $(100 \mu \mathrm{g})$ from two patient pools and two control pools was blocked, digested, and labeled according to the iTRAQ protocol (Applied Biosystems, Foster City, CA, USA). Four iTRAQ tagging reactions were prepared (Patient Pool 1-iTRAQ 117, Patient Pool 2-iTRAQ 118, Control Pool 1-iTRAQ 119 and Control Pool 2-iTRAQ 121), then all reactions were pooled into a single mixture, which was fractionated by multi-dimensional liquid chromatography involving a Zorbax Bio-SCX column $(35 \times 0.3 \mathrm{~mm}, 300 \AA$, $3.5 \mu \mathrm{m}$ particles; Agilent Technologies, Santa Clara, CA, USA) and a gradient of potassium formate in $25 \%$ acetonitrile, which generated 10 strong cation exchange fractions; these fractions were further separated on a Tempo ${ }^{\mathrm{TM}} \mathrm{LC}$ nanoflow and MALDI spotting system (Applied Biosystems) equipped with a reverse-phase Magic C18AQ column $(150 \times 0.2 \mathrm{~mm}, 200 \AA$, $3 \mu \mathrm{m}$ particles; Michrom Bioresources, CA, USA). Each multidimensional chromatography run yielded approximately 380 MALDI spots on a stainless steel MALDI target plate.

\section{Mass spectrometry}

Mass spectrometry was performed on an Applied Biosystems 4800 Plus MALDI TOF/TOF system. Only results associated with a signal-to-noise ratio of at least 40 were selected for tandem mass spectrometry. Mass spectra from 500 laser shots were acquired for each spot. The tandem mass spectrometry data from all 10 fractions were input into a Paragon algorithm search conducted using Protein Pilot ${ }^{\mathrm{TM}}$ 3.0 software (Applied Biosystems/MDS-Sciex) against a database of the International Protein Index (human, version 3.62) [20], which was downloaded from the EBI website (www.ebi.ac.Uk/IPI/IPIhelp.html). Only proteins identified with at least $95 \%$ confidence, or a ProtScore of 1.3, were analyzed in detail. Relative quantification of proteins was based on the ratio of peak areas of $m / z 117,118,119$, and 121 from tandem mass spectrometry spectra.

We used the following procedure to define the minimal difference in relative levels of a protein between patients and controls that would allow us to define a protein as linked to rheumatoid arthritis. Two equal amounts of 10-fraction mixtures (Applied Biosystems) were trypsindigested and labeled with iTRAQ reagents. The standard deviation (SD) of all the ratios of the labeled peptides was computed to be 0.15 . This led to a cut-off value of $2 \mathrm{SD}+1=1.3$ as the minimal foldchange in patients relative to controls necessary for defining a protein as up-regulated in disease. The reciprocal cut-off of 0.77 was used as the maximal fold-change in patients relative to controls necessary for defining a protein as down-regulated in disease. These same cut-offs were also used to filter out proteins that differed by more than 1.3 -fold or less than 0.77 -fold between the two patient pools and the two control pools (technical replicates).

\section{Bioinformatics analysis}

Candidate biomarkers of rheumatoid arthritis were functionally annotated based on the Gene Ontology (GO) classification system (http://wego.genomics.org.cn), and a network of interacting molecules was built using on-line Ingenuity Pathway Analysis (IPA, www. ingenuity.com).

\section{Results}

\section{Identification of protein expression changes by iTRAQ proteomic analysis}

A total of 3,208 proteins were identified from patient and control PBMC extracts, of which 42 were significantly up-regulated in rheumatoid arthritis and 41 were down-regulated (Table 1). Figure 1 shows a representative tandem mass spectrum of serotransferrin, one of the proteins up-regulated in disease. Figure 2 shows the spectrum of annexin $\mathrm{A} 2$, one of the proteins down-regulated in disease.

\section{Potential functions of proteins linked to rheumatoid arthritis}

GO analyses using the WEGO online tool indicated that the proteins significantly up- and down-regulated in patients relative to controls are involved in cellular and metabolic processes, biological regulation, and molecular functions of binding, catalysis and transport (Figure 3).

\section{Pathway and networks involving proteins linked to rheumatoid arthritis}

IPA was used to construct pathways and networks involving proteins significantly up- or down-regulated in rheumatoid arthritis in order to analyze their possible relationships (Figure 4). The pathways are focused on receptor signal activation and acute phase response signaling, while the six networks involve primarily organismal injury and abnormalities, immunological disease, cellular movement, connective tissue disorders, cell death and survival, post-translational modification, and cell-to-cell signaling and interaction (Figure 5).

\section{Discussion}

Little is known about proteins associated with the pathogenesis of rheumatoid arthritis, and several are likely to play key roles, given that

Table 1. Proteins showing the greatest fold-changes in patients with rheumatoid arthritis relative to healthy controls.

\begin{tabular}{|c|c|c|c|}
\hline No. & Accession code & Name & $\begin{array}{l}\text { Average folds } \\
\text { (arthritis/control) }\end{array}$ \\
\hline \multicolumn{4}{|c|}{ Top 10 proteins up-regulated in rheumatoid arthritis } \\
\hline 1 & $\mathrm{sp} \mid \mathrm{P} 01859$ & Ig gamma-2 chain $\mathrm{C}$ region & 4.823439138 \\
\hline 2 & $\mathrm{sp} \mid \mathrm{P} 02768$ & Serum albumin & 4.773611854 \\
\hline 3 & $\mathrm{sp} \mid \mathrm{P} 01834$ & Ig kappa chain $\mathrm{C}$ region & 4.750356564 \\
\hline 4 & $\mathrm{sp} \mid \mathrm{P} 02787$ & Serotransferrin & 4.667309404 \\
\hline 5 & $\mathrm{sp} \mid \mathrm{P} 00738$ & Haptoglobin & 4.089293455 \\
\hline 6 & $\mathrm{sp} \mid \mathrm{P} 01009$ & Alpha-1-antitrypsin & 3.903263238 \\
\hline 7 & $\mathrm{sp} \mid \mathrm{P} 01857$ & Ig gamma-1 chain $\mathrm{C}$ region & 3.803608909 \\
\hline 8 & $\mathrm{sp} \mid \mathrm{P} 01615$ & $\begin{array}{l}\text { Immunoglobulin kappa variable } \\
\text { 2D-28 }\end{array}$ & 3.693985617 \\
\hline 9 & $\mathrm{sp} \mid \mathrm{P} 01876$ & Ig alpha-1 chain $\mathrm{C}$ region & 3.424910075 \\
\hline 10 & $\mathrm{sp} \mid \mathrm{P} 02671$ & Fibrinogen alpha chain & 3.371755769 \\
\hline \multicolumn{4}{|c|}{ Top 10 proteins down-regulated in rheumatoid arthritis } \\
\hline 1 & sp|Q16777 & Histone $\mathrm{H} 2 \mathrm{~A}$ type $2-\mathrm{C}$ & 4.24889502 \\
\hline 2 & sp|P16402 & Histone H1.3 & 4.101023024 \\
\hline 3 & $\mathrm{sp} \mid \mathrm{P} 41218$ & $\begin{array}{l}\text { Myeloid cell nuclear differentiation } \\
\text { antigen }\end{array}$ & 3.913870339 \\
\hline 4 & sp|Q96L21 & 60S ribosomal protein L10-like & 3.653741806 \\
\hline 5 & $\mathrm{sp} \mid \mathrm{P} 18859$ & $\begin{array}{l}\text { ATP synthase-coupling factor } 6 \text {, } \\
\text { mitochondrial }\end{array}$ & 3.34532721 \\
\hline 6 & $\mathrm{sp} \mid \mathrm{P} 62266$ & $40 \mathrm{~S}$ ribosomal protein $\mathrm{S} 23$ & 3.209125754 \\
\hline 7 & $\mathrm{sp} \mid \mathrm{P} 06454$ & Prothymosin alpha & 3.192761477 \\
\hline 8 & $\mathrm{sp} \mid \mathrm{P} 61769$ & Beta-2-microglobulin & 3.176176391 \\
\hline 9 & sp|Q07020 & $60 \mathrm{~S}$ ribosomal protein $\mathrm{L} 18$ & 3.155362286 \\
\hline 10 & sp|Q9H299 & $\begin{array}{l}\text { SH3 domain-binding glutamic } \\
\text { acid-rich-like protein } 3\end{array}$ & 3.122316334 \\
\hline
\end{tabular}




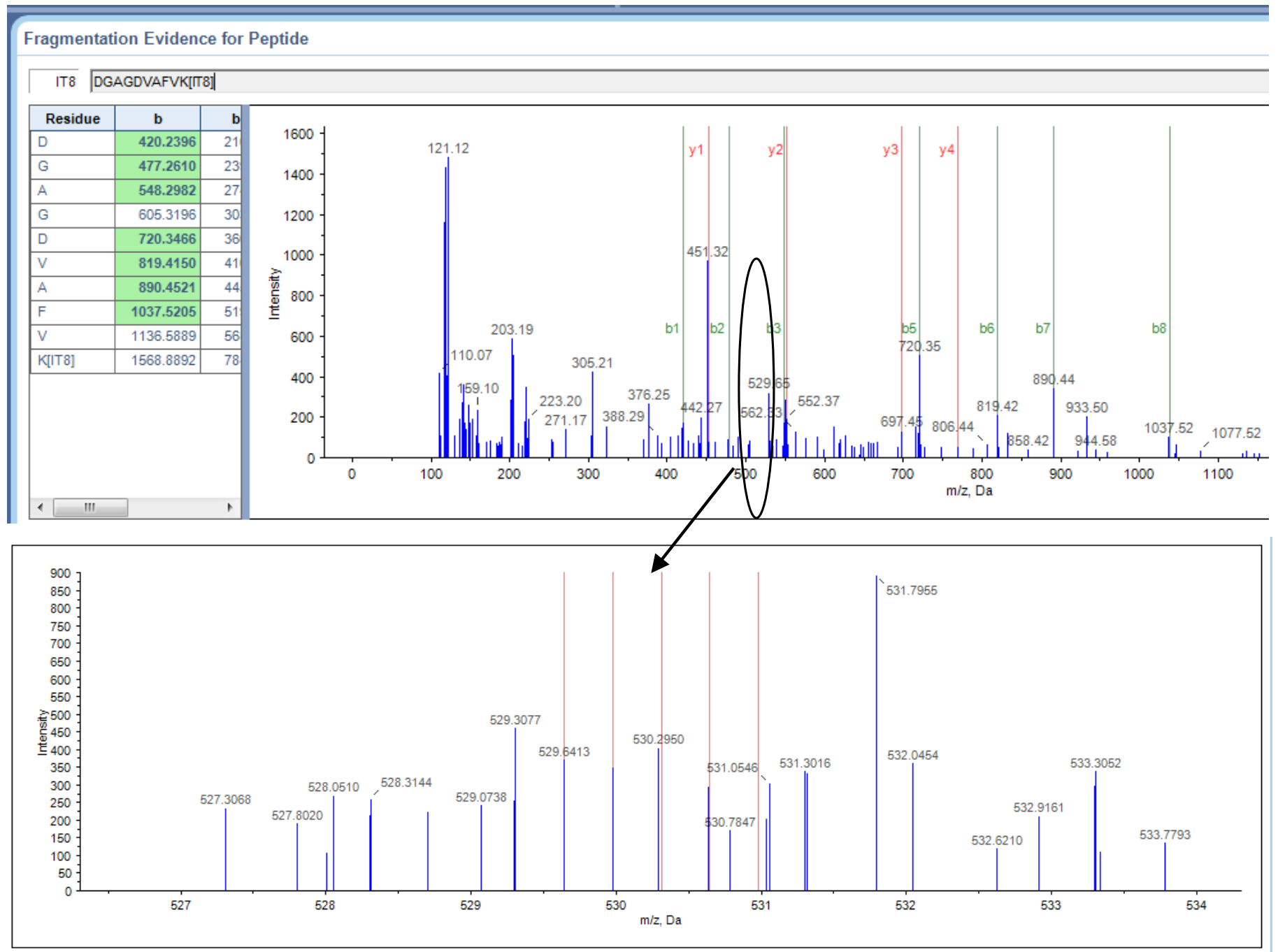

Figure 1. Serotransferrin sequencing and quantification using iTRAQ. A representative MALDI TOF/TOF MS/MS spectrum of the serotransferrin-derived peptide DGAGDVAFVK is shown with fragmented b-ions and y-ions.

the disease is likely to involve many genes. Here we identified several proteins significantly up- and down-regulated in the disease, providing the basis for further molecular studies aimed at identifying biomarkers useful for diagnosis, treatment and prognosis. While iTRAQ has proven effective at identifying disease biomarkers from tissue or serum [9-11,15,19,21-23], its usefulness for analyzing proteins from PBMCs is only beginning to be explored in the case of rheumatoid arthritis.

In this study, 83 proteins were identified as differentially expressed in rheumatoid arthritis. Most are inflammation-associated proteins and many were found to be up-regulated in the disease, including complement, immunoglobulin, and ribosomal protein. These proteins seem less useful as potential rheumatoid arthritis biomarkers, since they are also up-regulated in other auto-immune diseases. In contrast, other proteins that we identified as linked to rheumatoid arthritis merit further attention as biomarker candidates, including serotransferrin, clusterin, annexin A2, and heterogeneous nuclear ribonucleoprotein A2/B1.

GO analysis suggested that many of the proteins linked to rheumatoid arthritis in our study are involved in cellular and metabolic processes, biological regulation, and molecular functions related to binding, catalysis and transport. Interaction networks constructed from all 83 disease-linked proteins are involved primarily in organismal injury and abnormalities, immunological disease, cellular movement, connective tissue disorders, cell death and survival, post-translational modification, and cell-to-cell signaling and interaction.

Several proteins identified in our study as linked to rheumatoid arthritis have already been shown in previous work to contribute to pathogenesis of the disease. Clusterin, which was up-regulated in disease in our study, is expressed predominantly by synoviocytes and is present in synovial fluid. It promotes apoptosis and can regulate the NF-kappaB pathway, strongly affecting inflammation and immunity $[24,25]$. Annexin A3, which was up-regulated in disease in our study, induces migration and tube formation of human umbilical vein endothelial cells; transfecting cells with an annexin A3 expression plasmid leads to high levels of vascular endothelial growth factor (VEGF), a major angiogenic factor. Annexin A3 also enhances the transactivation activity of hypoxia-inducible factor-1 (HIF-1) [26]. The consistency between these previous studies and our own findings suggests that our iTRAQ results are reliable.

Some of the proteins down-regulated in rheumatoid arthritis in our study have previously been shown to be down-regulated in other 


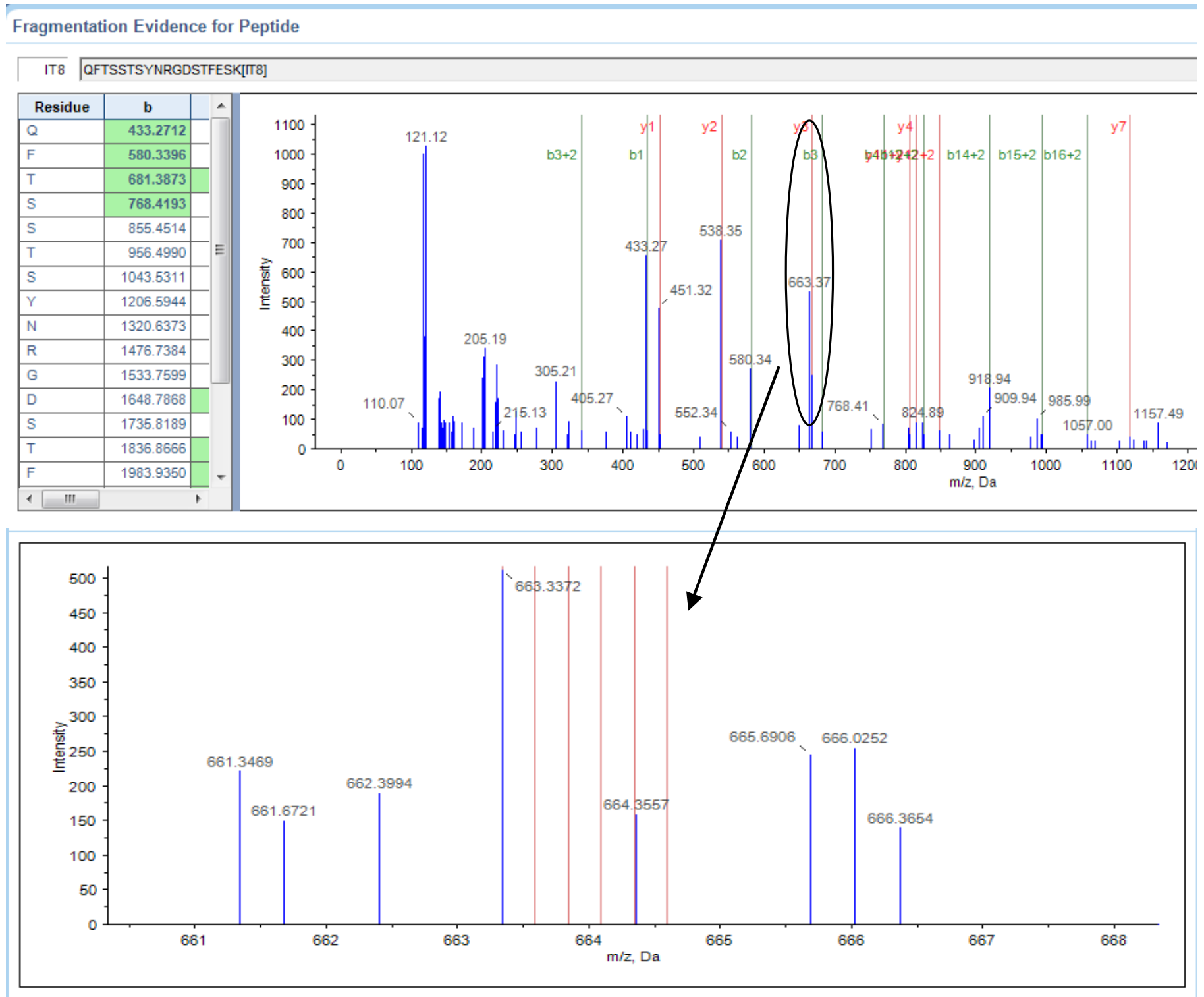

Figure 2. Annexin A2 sequencing and quantification using iTRAQ. A representative MALDI TOF/TOF MS/MS spectrum of the Annexin A2-derived peptide QFTSSTSYNRGDSTFESK is shown with fragmented b-ions and y-ions.

disease contexts. Prothymosin a exerts in vitro immunomodulatory effects on autoimmune diseases [27-29]. Cytochrome c oxidase (CytcO) is a multi-subunit enzyme that acts as both an $\mathrm{O}_{2}$ sensor and a regulatory enzyme that determines mitochondrial respiration capacity. Hypoxia inhibits CytcO expression in vitro [30], which is linked with joint inflammation and decreased vascularity [31,32]. Positively charged cytochrome $c$ and negatively charged truncated prothymosin a, when meeting in cytosol, can interact with each other. Truncated prothymosin $\alpha$ inhibits cytochrome $c$ oxidation by $\mathrm{H}_{2} \mathrm{O}_{2}$, catalyzed by peroxidase [33]. Down-regulation of $\mathrm{CytcO}$ has been reported in juvenile idiopathic arthritis [34] and inflammatory arthritis.

Our iTRAQ study identified some proteins, such as beta-2microglobulin, thymosin beta 4 and beta10, have not previously been linked to rheumatoid arthritis, but have been linked to other diseases. Examples are beta-2-microglobulin and thymosin $\beta 10$ [35-38]. These candidate rheumatoid arthritis biomarkers deserve further attention.

The goal of the present study was to identify a set of potential candidate biomarkers of rheumatoid arthritis that could be validated and further analyzed in future work involving other patient populations. Such work should verify and extend the present results by comparing protein levels in PBMC and serum between patients and controls.

\section{Conflicts of interest}

The authors declare no conflicts of interest.

\section{Acknowledgments}

Supported by Henan science and technology innovation team, Investigation on plant resources in Dabie Mountains and the study and utilization of active components of special plants, Nanhu Scholars Program for Young Scholars of XYNU 

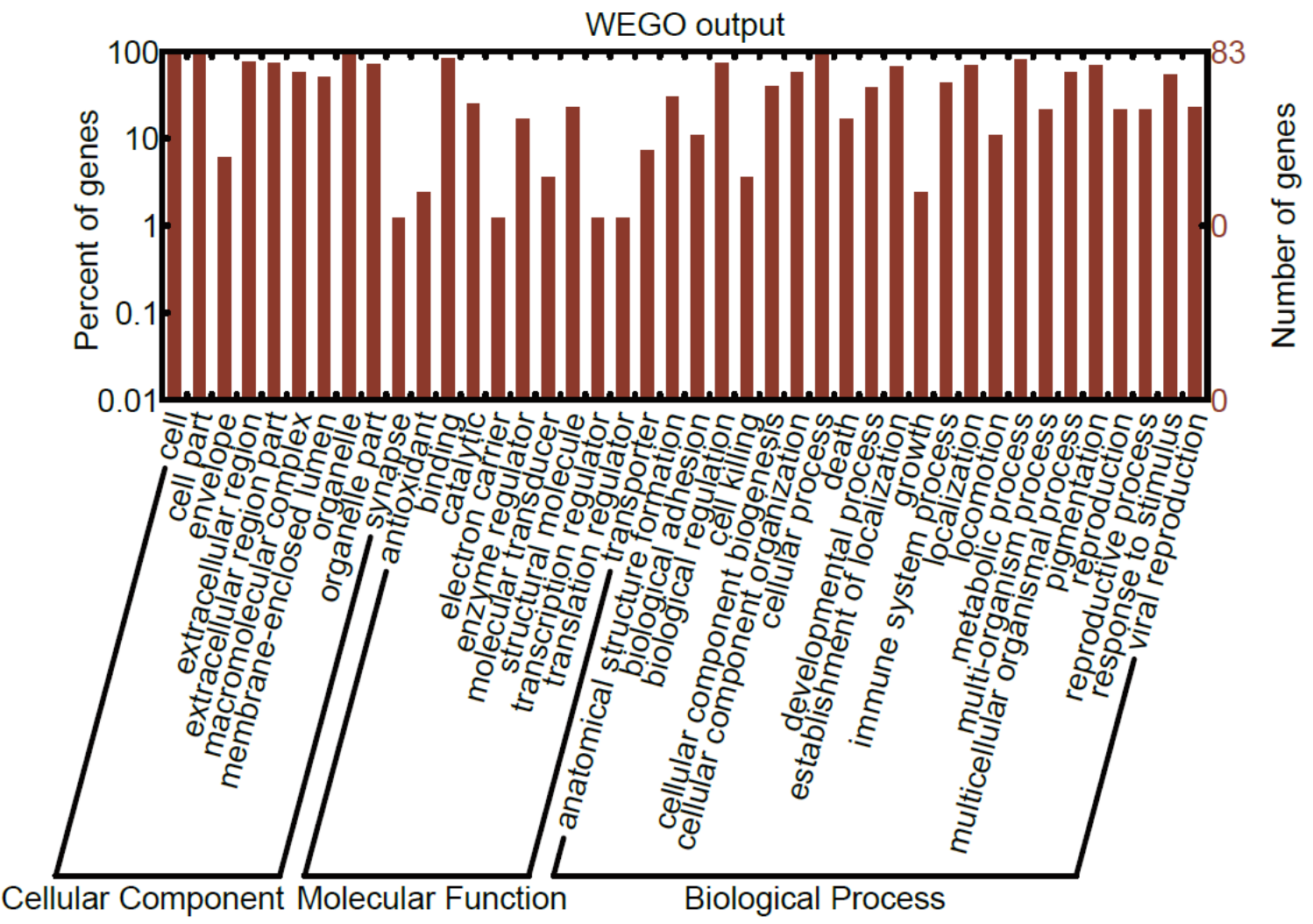

Figure 3. GO analysis of proteins significantly up- or down-regulated in rheumatoid arthritis

Analysis: RA-different proteins-2 - 2017-02-17 04:32 PM

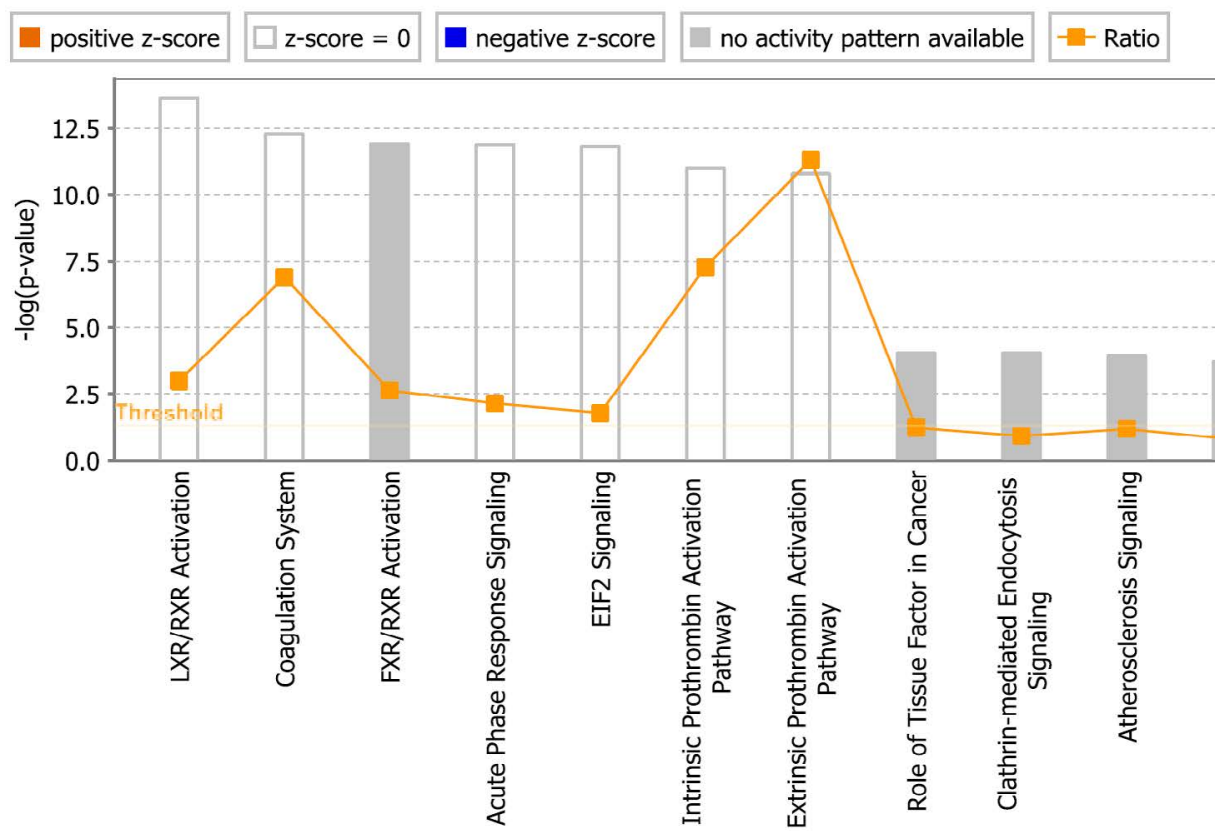

C) 2000-2017 QIAGEN. All rights reserved.

Figure 4. Signaling pathways involving proteins significantly up- or down-regulated in rheumatoid arthritis. 

Network 1 : RA-different proteins-2017 - 2017-02-17 01:40 PM : RA-different proteins-2017 : RA-different proteins-2017 - 2017-02-17 0.
40 PM

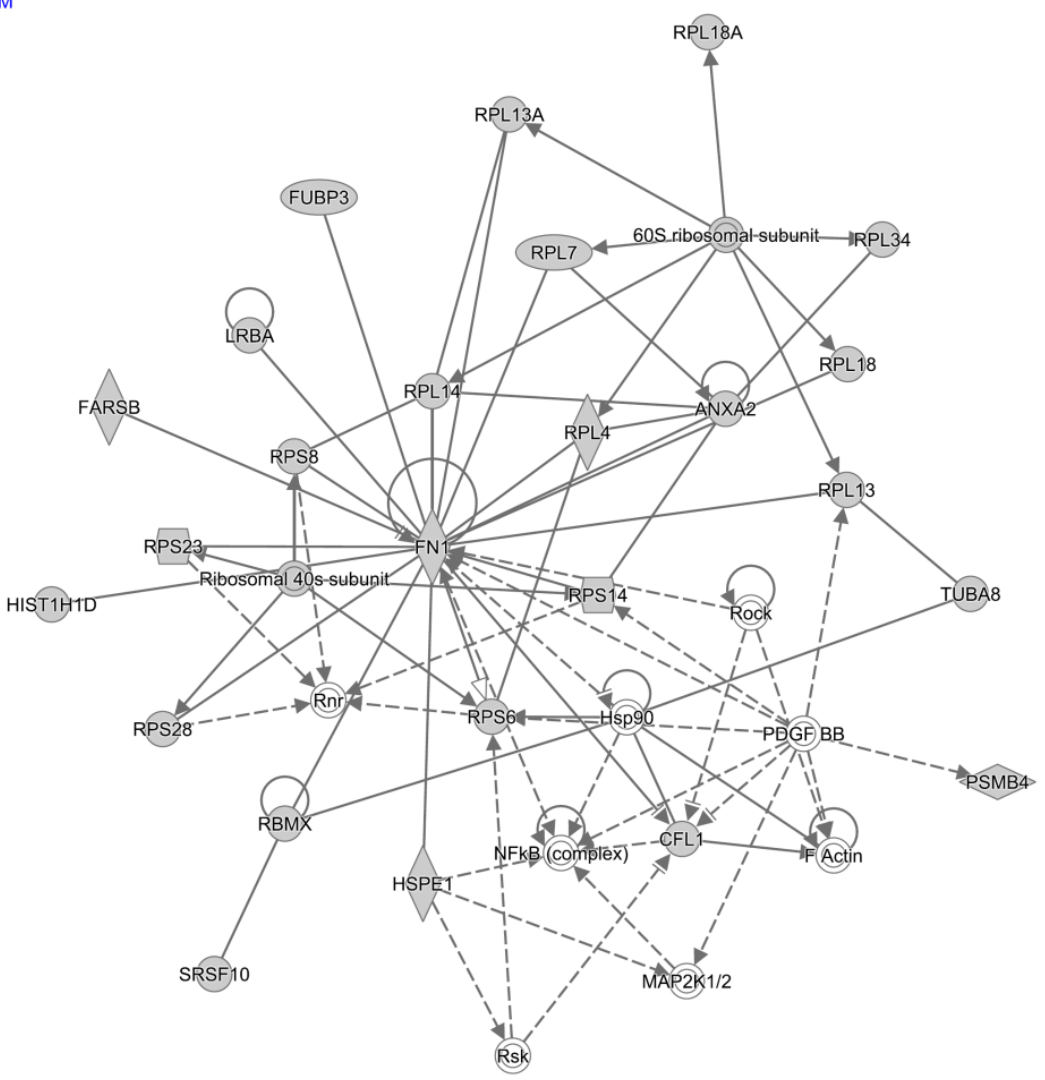

(-) 2000-2017 QIAGEN. All rights reserved.

Network 2 : RA-different proteins-2017 - 2017-02-17 01:40 PM : RA-different proteins-2017 : RA-different proteins-2017 - 2017-02-17 01:40 PM

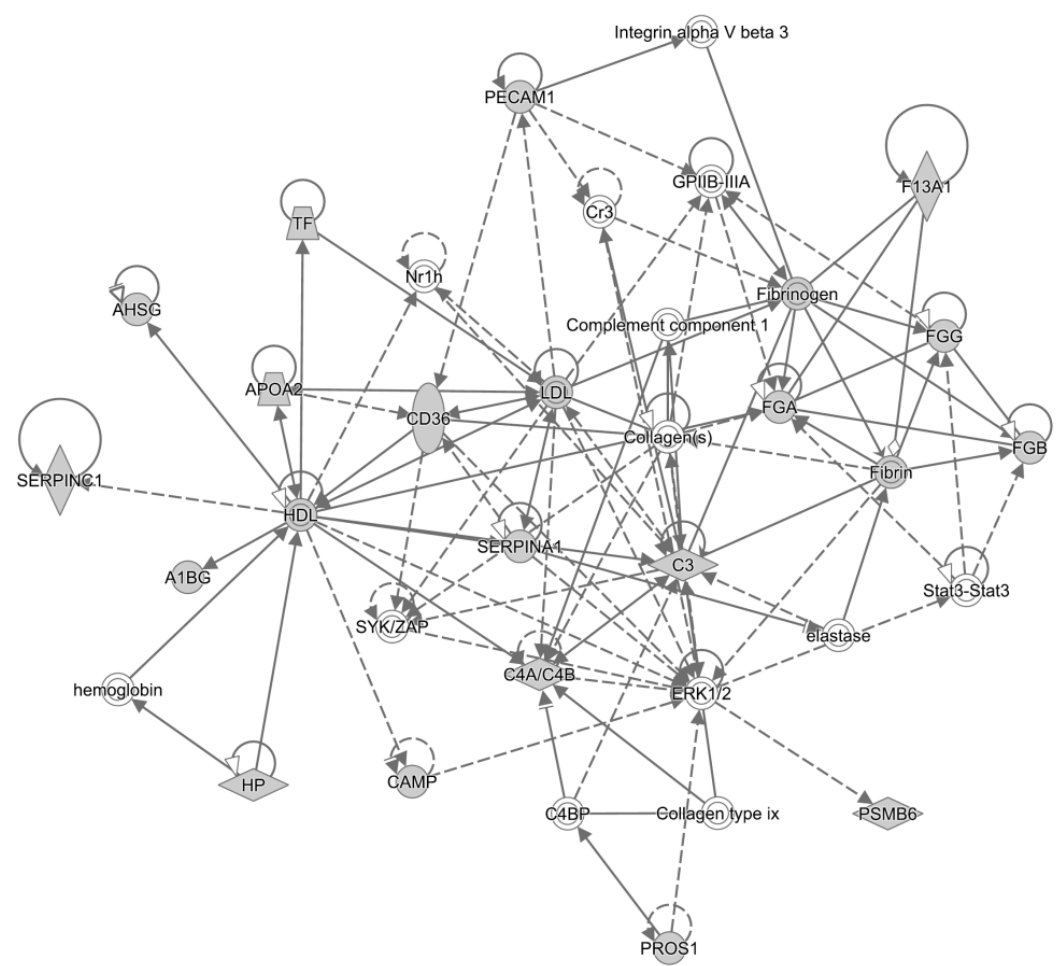

Figure 5. Two networks involving proteins significantly up- or down-regulated in rheumatoid arthritis. 


\section{References}

1. Catrina AI, Svensson CI, Malmstrom V, Schett G, Klareskog L (2017) Mechanisms leading from systemic autoimmunity to joint-specific disease in rheumatoid arthritis. Nat Rev Rheumatol 13: 79-86. [Crossref]

2. Lenert A, Lenert P (2017) Tapering biologics in rheumatoid arthritis: a pragmatic approach for clinical practice. Clin Rheumatol 36: 1-8. [Crossref]

3. Venuturupalli S1 (2017) Immune Mechanisms and Novel Targets in Rheumatoid Arthritis. Immunol Allergy Clin North Am 37: 301-313. [Crossref]

4. Wu DJ, Adamopoulos IE (2017) Autophagy and autoimmunity. Clin Immunol 176: 5562. [Crossref]

5. Zouali M, Tsay G (2016) Developing connections amongst B lymphocytes and deregulated pathways in autoimmunity. Mol Med 22. [Crossref]

6. Salomon S, Guignant C, Morel P, Flahaut G, Brault C, et al. (2017) Th17 and CD24hiCD27+ regulatory B lymphocytes are biomarkers of response to biologics in rheumatoid arthritis. Arthritis Res Ther 19:33. [Crossref]

7. Ren CF, Zhao YX, Hou CF, Luan L, Duan GQ, et al. (2017) Expression of soluble programmed death-1 protein in peripheral blood regulatory $\mathrm{T}$ cells and its effects on rheumatoid arthritis progression. Mol Med Rep 15: 460-466.

8. Deng Y, Wang Z, Chang C, Lu L, Lau CS, et al. (2017) Th9 cells and IL-9 in autoimmune disorders: Pathogenesis and therapeutic potentials. Hum Immunol 78: 120-128. [Crossref]

9. Zhang Y, Cai Y, Yu H, Li H (2015) iTRAQ-Based Quantitative Proteomic Analysis Identified HSC71 as a Novel Serum Biomarker for Renal Cell Carcinoma. Biomed Res Int 2015: 802153.

10. Cai A, Qi S, Su Z, Shen H, Yang Y, et al. (2015) Quantitative Proteomic Analysis of Peripheral Blood Mononuclear Cells in Ankylosing Spondylitis by iTRAQ. Clin Transl Sci 8: 579-583. [Crossref]

11. Zhao M, Xu F, Wu F, Yu D (2016) iTRAQ-Based Membrane Proteomics Reveals Plasma Membrane Proteins Change During HepaRG Cell Differentiation. J Proteome Res 15: 4245-4257. [Crossref]

12. Minjarez B, Calderon-Gonzalez KG, Rustarazo ML, Herrera-Aguirre ME, LabraBarrios ML, et al. (2016) Identification of proteins that are differentially expressed in brains with Alzheimer's disease using iTRAQ labeling and tandem mass spectrometry. J Proteomics 139: 103-121. [Crossref]

13. Sui W, Tang D, Zou G, Chen J, Ou M, et al. (2012) Differential proteomic analysis of renal tissue in lupus nephritis using iTRAQ reagent technology. Rheumatol Int 32: 3537-3543. [Crossref]

14. Tremlett H, Dai DL, Hollander Z, Kapanen A, Aziz T, et al. (2015) Serum proteomics in multiple sclerosis disease progression. J Proteomics 118: 2-11. [Crossref]

15. Serada S, Naka T (2014) Screening for novel serum biomarker for monitoring disease activity in rheumatoid arthritis using iTRAQ technology-based quantitative proteomic approach. Methods Mol Biol 1142: 99-110. [Crossref]

16. Serada S, Fujimoto M, Ogata A, Terabe F, Hirano T, et al. (2010) iTRAQ-based proteomic identification of leucine-rich alpha-2 glycoprotein as a novel inflammatory biomarker in autoimmune diseases. Ann Rheum Dis 69: 770-774. [Crossref]

17. Rocha B, Ruiz-Romero C, Blanco FJ (2017) Mass spectrometry imaging: a novel technology in rheumatology. Nat Rev Rheumatol 13: 52-63. [Crossref]

18. Yakkioui Y, Temel Y, Chevet E, Negroni L (2017) Integrated and Quantitative Proteomics of Human Tumors. Methods Enzymol 586: 229-246.

19. Wang L, Dai Y, Qi S, Sun B, Wen J, et al. (2012) Comparative proteome analysis of peripheral blood mononuclear cells in systemic lupus erythematosus with iTRAQ quantitative proteomics. Rheumatol Int 32: 585-593. [Crossref]
20. Kersey PJ, Duarte J, Williams A, Karavidopoulou Y, Birney E (2004) The International Protein Index: an integrated database for proteomics experiments. Proteomics 4: 19851988. [Crossref]

21. Wang Q, Su X, Jiang X, Dong X, Fan Y, et al. (2016) iTRAQ technology-based identification of human peripheral serum proteins associated with depression. Neuroscience 330: 291-325. [Crossref]

22. Niu R, Liu Y, Zhang Y, Zhang Y, Wang H, et al. (2017) iTRAQ-Based Proteomics Reveals Novel Biomarkers for Idiopathic Pulmonary Fibrosis. PLoS One 12: e0170741. [Crossref]

23. Shen L, Liao L, Chen C, Guo Y, Song D, et al. (2017) Proteomics Analysis of Blood Serums from Alzheimer's Disease Patients Using iTRAQ Labeling Technology. J Alzheimers Dis 56: 361-378. [Crossref]

24. Falgarone G, Chiocchia G (2009) Chapter 8: Clusterin: A multifacet protein at the crossroad of inflammation and autoimmunity. Adv Cancer Res 104: 139-170. [Crossref]

25. Devauchelle V, Essabbani A, De Pinieux G, Germain S, Tourneur L, et al. (2006) Characterization and functional consequences of underexpression of clusterin in rheumatoid arthritis. J Immunol 177: 6471-6479. [Crossref]

26. Park JE, Lee DH, Lee JA, Park SG, Kim NS, et al. (2005) Annexin A3 is a potential angiogenic mediator. Biochem Biophys Res Commun 337: 1283-1287. [Crossref]

27. Samara P, Ioannou K, Tsitsilonis OE (2016) Prothymosin Alpha and Immune Responses: Are We Close to Potential Clinical Applications? Vitam Horm 102: 179207. [Crossref]

28. Shiau AL, Chen SY, Chang MY, Su CH, Chung SY, et al. (2007) Prothymosin alpha lacking the nuclear localization signal as an effective gene therapeutic strategy in collagen-induced arthritis. J Immunol 178: 4688-4694. [Crossref]

29. Niture SK, Jaiswal AK (2017) Prothymosin-alpha mediates nuclear import of the INrf2/ Cul3.Rbx1 complex to degrade nuclear Nrf2. J Biol Chem 292: 2049. [Crossref]

30. Biniecka M, Fox E, Gao W, Ng CT, Veale DJ, et al. (2011) Hypoxia induces mitochondrial mutagenesis and dysfunction in inflammatory arthritis. Arthritis Rheum 63: 2172-2182. [Crossref]

31. Kennedy A, Ng CT, Biniecka M, Saber T, Taylor C, et al. (2010) Angiogenesis and blood vessel stability in inflammatory arthritis. Arthritis Rheum 62: 711-721. [Crossref]

32. Ng CT, Biniecka M, Kennedy A, McCormick J, Fitzgerald O, et al. (2010) Synovia tissue hypoxia and inflammation in vivo. Ann Rheum Dis 69: 1389-1395. [Crossref]

33. Markova OV, Evstafieva AG, Mansurova SE, Moussine SS, Palamarchuk LA, et al. (2003) Cytochrome $\mathrm{c}$ is transformed from anti- to pro-oxidant when interacting with truncated oncoprotein prothymosin alpha. Biochim Biophys Acta 1557: 109-117. [Crossref]

34. Ishikawa S, Mima T, Aoki C, Yoshio-Hoshino N, Adachi Y, et al (2009) Abnormal expression of the genes involved in cytokine networks and mitochondrial function in systemic juvenile idiopathic arthritis identified by DNA microarray analysis. Ann Rheum Dis 68: 264-272. [Crossref]

35. Monteiro MB, Thieme K, Santos-Bezerra DP, Queiroz MS, Woronik V, et al. (2016) Beta-2 microglobulin (B2M) expression in the urinary sediment correlates with clinical markers of kidney disease in patients with type 1 diabetes. Metabolism 65: 816-824. [Crossref]

36. Kanemasa Y, Shimoyama T, Sasaki Y, Tamura M, Sawada T, et al. (2016) Beta-2 microglobulin as a significant prognostic factor and a new risk model for patients with diffuse large B-cell lymphoma. Hematol Oncol 35: 440-446. [Crossref]

37. Prizment AE, Linabery AM, Lutsey PL, Selvin E, Nelson HH, et al. (2016) Circulating Beta-2 Microglobulin and Risk of Cancer: The Atherosclerosis Risk in Communities Study (ARIC). Cancer Epidemiol Biomarkers Prev 25: 657-664. [Crossref]

38. Bosello S, Peluso G, Iavarone F, Tolusso B, Messana I, et al. (2016) Thymosin beta4 and beta10 in Sjogren's syndrome: saliva proteomics and minor salivary glands expression. Arthritis Res Ther 18: 229. [Crossref]

Copyright: (C2018 Xinqiang S. This is an open-access article distributed under the terms of the Creative Commons Attribution License, which permits unrestricted use, distribution, and reproduction in any medium, provided the original author and source are credited. 